\title{
Herneen viljelyn laajeneminen lisää hernekääriäisriskiä
}

\author{
Erja Huusela-Veistola ${ }^{1)}$ ja Lauri Jauhiainen ${ }^{2)}$ \\ ${ }^{1)}$ MTT Kasvinsuojelu, 31600 Jokioinen, erja.huusela-veistola@mtt.fi \\ ${ }^{2)}$ MTT Tietopalvelut, 31600 Jokioinen, lauri.jauhiainen@mtt.fi
}

\section{Tiivistelmä}

MTT:ssä vuosina 2002-2004 tehdyn "Kotimaista valkuaista herneestä"-tutkimushankkeen tulosten perusteella herneen viljelyn laajentamiselle ja rehukäytön lisäämiselle Suomessa on olemassa edellytyksiä. Herneen viljelyn mahdollinen laajeneminen voi kuitenkin lisätä herneen kasvinsuojeluongelmia. Tässä esitettävän osatutkimuksen tavoitteena oli selvittää ja ennakoida rehuherneen viljelyn ja herneen viljelyalan kasvun vaikutuksia hernekääriäisriskiin.

Hernekääriäisen esiintymistä tutkittiin käytännön herneviljelyksillä Varsinais-Suomessa, Hämeessä, Satakunnassa ja Uudellamaalla. Hernekääriäismääriä havainnoitiin 93 pellolla vuonna 2002 ja 90 pellolla vuonna 2003. Otantaan sisältyi ruokaherne-, rehuherne- ja seoskasvustoja. Tutkimuslohkoista kolmannes oli luomuviljeltyjä. Tutkimuslohkojen valinnassa käytettiin apuna peltoherneen viljelytietoja vuosilta 1997-2001. Niiden perusteella valittiin satunnaisesti tutkimuslohkoja herneen viljelyintensiteetin (viljelyala ja frekvenssi) suhteen erilaisilta alueilta. Tutkimuslohkojen hernekääriäismääriä arvioitiin feromonipyydyksillä kesäkuun alusta elokuun alkuun. Lisäksi tiloilta kerätyistä kasvi- ja satonäytteistä määritettiin hernekääriäisvioitukset.

Hernekääriäismäärät feromonipyydyksissä olivat selvästi pienempiä vuonna 2003 (keskimäärin 126 kpl/ansa) kuin vuonna 2002 (244 kpl/ansa), jolloin hernekääriäisen lento alkoi aikaisemmin. Hernekääriäismäärät feromonipyydyksissä ja vioittuneiden siementen osuus kasvoivat lineaarisesti kun edellisvuoden herneen viljelyala lähialueella (4 km:n säteellä) kasvoi. Vastaavasti hernekääriäisten runsaus ja vioitusten määrä vähenivät eksponentiaalisesti, kun etäisyys lähimpään edellisvuoden hernelohkoon kasvoi. Hernekääriäisen vioittamia palkoja ja herneitä oli merkitsevästi enemmän luomulohkoilla (v. 200226 \%; v. 2003 13\% ) kuin tavanomaisesti viljellyillä lohkoilla (v. 200217 \%; v. 2003 4 \%), vaikka feromonipyydyssaalissa ei merkitsevää eroa tuotantotapojen välillä ollut. Oikein ajoitettu hyönteistorjuntaaineiden käyttö vähensi tehokkaasti vioittuneiden palkojen ja herneiden määrää.

Tulosten perusteella hernekääriäisriski on selvästi suurempi alueilla, joilla herneen viljely on yleistä. Herneen viljelyalan ja -frekvenssin mahdollinen kasvu lisää hernekääriäisen torjuntatarvetta. Kemiallinen torjunta onnistuu parhaiten, kun insektisidikäsittely ajoitetaan lohkokohtaisesti feromonipyydystarkkailun avulla. Ennakoivana torjuntakeinona suositellaan alueellista viljelykiertoa, joka huomioi edellisen vuoden hernelohkojen sijainnin laajemmin kuin lohkokohtainen viljelykierto. Hernekääriäistuhojen välttämiseksi uusi hernelohko pitää perustaa mahdollisimman kauas, vähintään 1,5 km:n päähän, edellisvuoden hernelohkosta ja rehuhernelohkot riittävän etäälle ruoka- ja siemenhernelohkoista.

\section{Asiasanat}

hernekääriäinen, Cydia nigricana, Pisum sativum, kasvinsuojelu, riskinarviointi, viljelyala, spatiaalisuus 


\section{Johdanto}

MTT:n johtamassa tutkimushankkeessa "Kotimaista valkuaista herneestä” (2002-2004) tutkittiin herneen viljelyn ja rehukäytön laajentamismahdollisuuksia. Hankkeen tavoitteisiin kuului herneen satovarmuuden ja viljelyn kannattavuuden parantaminen sekä viljelyn laajenemiseen liittyvien kasvinsuojeluriskien ennakointi. Kasvinsuojeluosion perustana oli vuosina 2002-2003 tehty hernepeltojen kasvintuhoojakartoitus peltoherneen pääviljelyalueella Etelä- ja Lounais-Suomessa. Kasvinsuojelututkimuksen tarkoituksena oli selvittää herneen kasvitautien, tuhoeläinten ja rikkakasvien esiintymisrunsautta ja torjuntaa sekä ennakoida kasvintuhoojista aiheutuvia ongelmia rehuherneen viljelyn mahdollisesti laajetessa.

Hernekääriäinen, Cydia nigricana (F.) (aiemmin Laspeyresia nigricana Steph.), on herneen pahin tuhoeläin, jonka aiheuttamat vioitukset huonontavat sekä sadon määrää että laatua. Hernekääriäisen merkitys riippuu herneen käyttötavasta. Eniten haittaa siitä on tuorehernetuotannossa, jossa sen torjuntakynnys on pienempi kuin kuivana korjattavan ruoka- tai siemenherneen tuotannossa. Rehuherneen viljelyssä hernekääriäistä ei tavallisesti torjuta lainkaan, mikä voi lisätä tuholaispainetta lähialueen muilla herneviljelyksillä. Tässä tutkimuksessa keskityttiin hernekääriäisen riskinarviointiin suhteessa herneenviljelyn oletettuun laajenemiseen.

\section{Aineisto ja menetelmät Koepellot ja otanta}

Herneen kasvintuhoojakartoitus toteutettiin vuosina 2002 ja 2003 käytännön herneviljelyksillä VarsinaisSuomessa, Hämeessä, Satakunnassa ja Uudellamaalla. Hernekääriäismääriä havainnoitiin 93 pellolla vuonna 2002 ja 90 pellolla vuonna 2003. Otantaan sisältyi ruokaherne-, rehuherne- ja seoskasvustoja. Tutkimuksessa mukana olleet pellot valittiin vuosien 1997-2001 herneenviljelytietojen perusteella (TIKE 2002). Kaikki vuosien 1997-2001 hernepellot jaettiin neljään yhtä suureen herneenviljelyn yleisyysluokkaan. Luokittelu perustui 4 km:n säteellä lohkon keskipisteestä sijaitsevien hernelohkojen lukumäärään ja pinta-alaan. Luokituksen tarkoituksena oli varmistaa, ettei otanta painotu liikaa alueelle, jossa herneen viljely on runsasta. Myöhemmin tulosten analysoinnissa käytettiin jatkuvaa yleisyysindeksiä, joka oli tietyllä etäisyydellä (2, 3 tai 4 km:n säteellä) sijaitsevien hernelohkojen pinta-ala suhteessa kokonaisalaan.

Lohkojen oletettiin olevan toisistaan spatiaalisesti riippumattomia, jos peltojen etäisyys oli vähintään 4 km. Tarkoituksena oli kerätä toisistaan spatiaalisesti riippumattomia havaintoja, sillä riippumattomat havainnot sisältävät enemmän informaatiota kuin toisistaan riippuvat havainnot. Ensimmäisen vuoden jälkeen hernekääriäisdatan riippumattomuus testattiin variogrammien avulla (Webster \& Oliver 2001). Jälkimmäisenä vuonna otanta tehtiin pääosin samoilla tiloilla kuin edellisenä vuonna, mutta mukana oli 21 uutta tilaa.

\section{Hernekääriäisseurannat}

Aikuisten hernekääriäisten esiintymistä tarkkailtiin feromonipyydyksillä kesäkuun alusta elokuun alkuun. Feromonipyydysten liimalevyt vaihdettiin kahden viikon välein. Feromoniseurantajakson päätteeksi otettiin kasvinäytteet (25 kasvia/pelto), joista laskettiin hernekääriäisen vioittamien palkojen osuus. Hernekääriäisvioitukset tarkastettiin myös 2 kg satonäytteistä otetuista 500 g osanäytteistä. Satonäytteet kerättiin 70 pellolta vuonna 2002 ja 81 pellolta vuonna 2003.

\section{Tilastolliset menetelmät}

Havaintoja kerättiin kahtena peräkkäisenä vuonna. Tilastollisiin malleihin sisällytettiin luokittelevana tekijänä tarpeen mukaan vuosi, tuotantomuoto (luomu/tavanomainen) ja/tai insektsidien käyttö.

Alkuperäisten neljän herneenviljelyn yleisyysluokan välisiä eroja analysoitiin täydellisesti satunnaistetun koemallin mukaisella varianssianalyysillä. Jatkuvan yleisyysindeksin analyysit tehtiin regressioanalyysillä, jossa oli mukana luokittelevat tekijät, indeksin lineaarinen vaikutus sekä niiden yhdysvaikutukset. Neljän kilometrin etäisyyteen perustuva yleisyysindeksi CAI ${ }_{4 k m}$ (continuous abundance index) osoittautui Akaiken informaatiokriteerin mukaisesti parhaimmaksi ja sitä käytettiin lopullisissa malleissa.

Graafisen tarkastelun perusteella hernekääriäisriskin suhde etäisyyteen edellisvuoden hernelohkosta ei ollut lineaarinen. Täten yhteyttä mallinnettiin kuuden epälineaarisen mallia avulla. Malleja vertailtiin Akaiken informaatiokriteerin avulla ja parhaaksi osoittautui eksponentiaalinen malli: 
$\mathrm{y}_{\mathrm{ij}}=\mathrm{a}_{\mathrm{j}} \exp \left(-\right.$-etäisyys $\left.\mathrm{sij}_{\mathrm{j}} / \mathrm{b}_{\mathrm{j}}\right)+\mathrm{e}_{\mathrm{ij}}$

missä $y_{\mathrm{ij}}$ on havaittu riski i. peltolohkolla j. ryhmässä. Etäisyys $\mathrm{ij}_{\mathrm{j}}$ on etäisyys lähimpään edellisen vuoden hernelohkoon, $a_{j}$ on käyrän maksimiarvo ja $b_{j}$ kuvaa sitä, kuinka nopeasti käyrä hiipuu kohti nollaa.

Herneen viljelyalan kaksinkertaistava skenaario tehtiin lisäämällä satunnaisesti enintään 10 km:n etäisyydelle kustakin jo olemassa olevasta hernelohkosta uusi samankokoinen hernelohko. Viljelyalan nelinkertaistavassa skenaariossa kutakin olemassa olevaa lohkoa kohti lisättiin 3 uutta lohkoa.

\section{Tulokset ja tulostentarkastelu}

\section{Herneen viljely vuosina 2002 ja 2003}

Peltoherneen kokonaisviljelyala oli 5075 ha vuonna 2002 ja 4115 ha vuonna 2003 (TIKE 2004). Vastaavasti tuoreherneen viljelyalat olivat 2392 ha ja 2374 ha, ja palkokasvi-vilja-seoskasvustojen viljelyalat 4000 ha ja 3700 ha (Maatilatilastollinen vuosikirja 2003). Tutkimuksessa mukana olleiden peltojen kokonaisala oli 418 ha vuonna 2002 ja 379 ha vuonna 2003, mikä oli lähes 10 \% herneen koko viljelyalasta. Koska herneen viljely keskittyy Etelä- ja Lounais-Suomeen, tutkittu ala käytännössä edusti yli puolta peltoherneen viljelyalasta.

Tutkimuksessa oli mukana 93 hernelohkoa vuonna 2002 ja 90 lohkoa vuonna 2003. Kumpanakin vuonna mukana oli 32 luomuviljeltyä lohkoa. Kemiallinen tuholaistorjunta tehtiin 39 \%:lla tavanomaisista tutkimuslohkoista vuonna 2002 ja 55 \%:Ila vuonna 2003.

\section{Hernekääriäisriski}

Hernekääriäismäärät feromonipyydyksissä olivat selvästi pienempiä vuonna 2003 (keskimäärin 126 kpl/ansa) kuin vuonna 2002 (244 kpl/ansa), jolloin hernekääriäisen lento alkoi aikaisemmin. Hernekääriäisen vioittamia palkoja ja herneitä oli merkitsevästi enemmän luomulohkoilla (v. 2002 26 \% ; v. 2003 13\% ) kuin tavanomaisesti viljellyillä lohkoilla (v. 200217 \% ; v. 20034 \%).

Hernekääriäismäärät feromonipyydyksissä kasvoivat lineaarisesti kun herneen viljelyn yleisyyttä kuvaava indeksi CAI $\mathrm{I}_{4 \mathrm{~km}}$ kasvoi (Kuva 1) . Vaikutus oli selvempi vuonna 2002 kuin 2003 (vuosi: $\mathrm{P}=0,02$; vuosi $\mathrm{x} \mathrm{CAI}_{4 \mathrm{~km}}: \mathrm{P}=0,04$ ) ja sellaisilla pelloilla, joilla ei käytetty hyönteistorjunta-ainetta (insektisidi: $\mathrm{P}=$ 0,04; insektisidi $x \mathrm{CAI}_{4 \mathrm{~km}}$ : $\mathrm{P}<0,01$ ). Luomupelloilla vioittuneiden herneiden osuus kasvoi myös lineaarisesti yleisyysindeksin $\mathrm{CAI}_{4 \mathrm{~km}}$ kasvaessa, mutta tavanomaisilla lohkoilla vaikutusta ei havaittu (tuotantomuoto $\left.\times \mathrm{CAI}_{4 \mathrm{~km}}: \mathrm{P}=0,02\right)$.

a) 2002

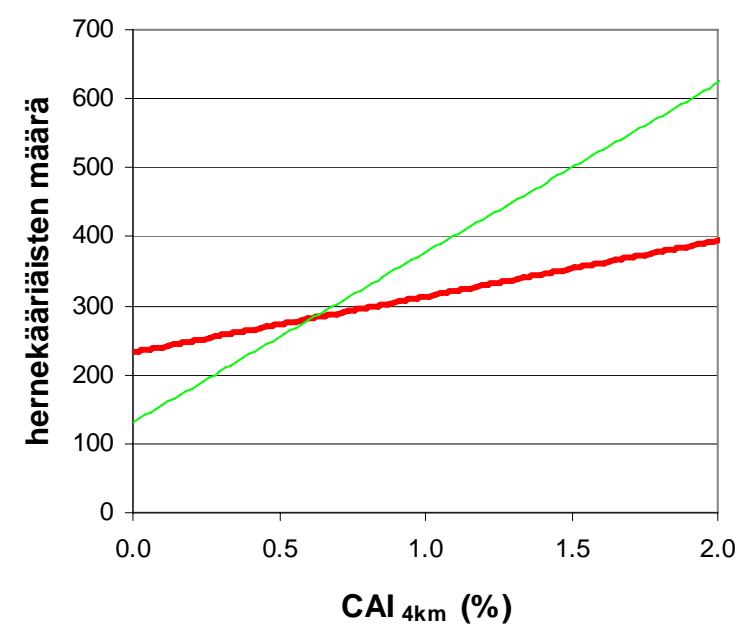

b) 2003

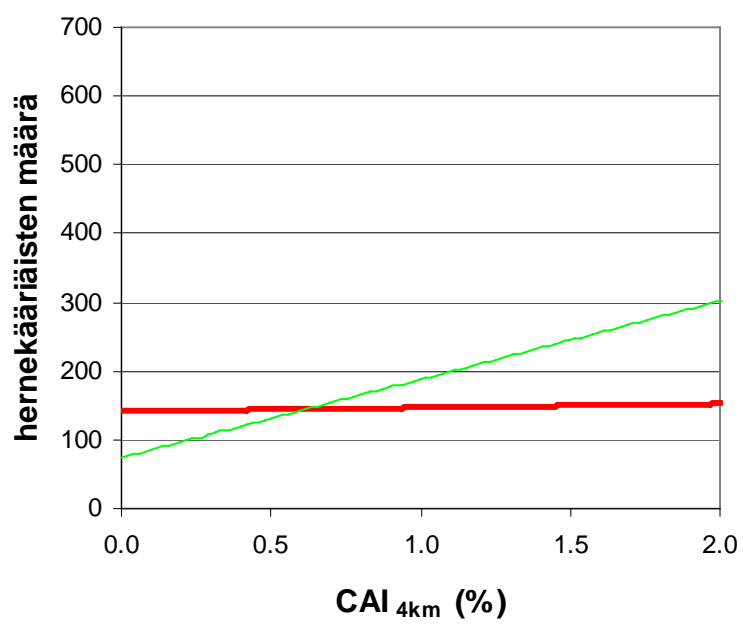

Kuva 1. Hernekääriäisrunsaus feromonipyydyksissä suhteessa viljelyn yleisyysindeksiin (CAI 4 km $)$ vuonna a) 2002 ja b) 2003. $\mathrm{CAI}_{4 \mathrm{~km}}=4 \mathrm{~km}: n$ säteellä sijaitsevien hernelohkojen pinta-ala suhteessa kokonaisalaan. 
Feromonipyydyksien koko kesän hernekääriäismäärät vähenivät eksponentiaalisesti kun etäisyys lähimpään edellisvuoden hernelohkoon kasvoi (Kuva 2). Trendissä oli kuitenkin selvä ero vuosien välillä, mikä johtui vuoden 2002 selvästi suuremmista hernekääriäismääristä. Hernekääriäisriski pieneni huomattavasti, kun etäisyys edellisvuoden hernelohkoon saavutti vuodesta riippuen 1-3 km. Myös hernekääriäisen vioittamien palkojen ja herneiden osuus väheni eksponentiaalisesti, kun etäisyys edellisvuoden hernelohkoon kasvoi. Trendiin kuitenkin vaikutti vuosi ja tuotantomuoto (luomu/tavanomainen) (Kuva 3).

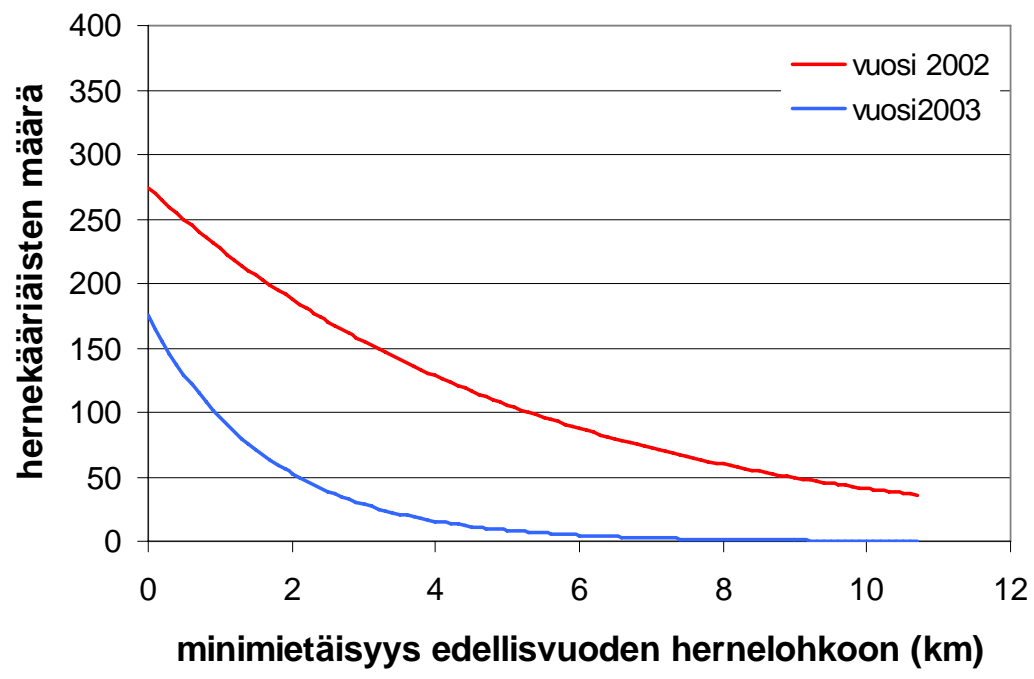

Kuva 2. Hernekääriäisrunsaus feromonipyydyksessä suhteessa etäisyyteen lähimmästä edellisvuoden hernelohkosta vuosina 2002 ja 2003.

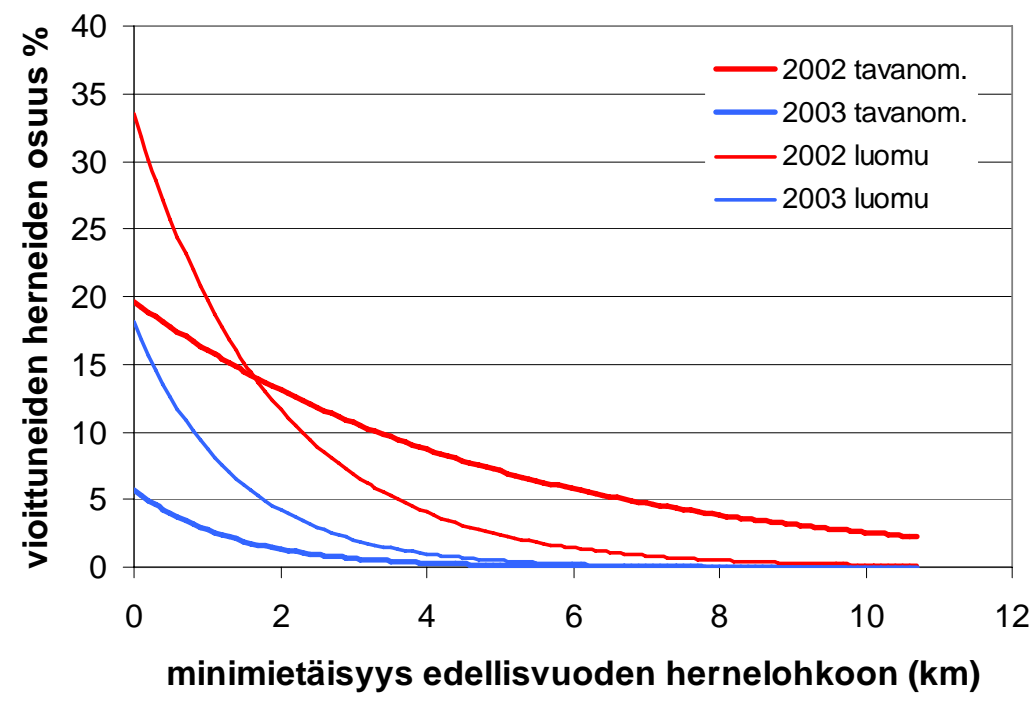

Kuva 3. Hernekääriäisen vioittamien herneiden osuus suhteessa etäisyyteen lähimmästä edellisvuoden hernelohkosta luonnonmukaisesti ja tavanomaisesti viljellyillä lohkoilla vuosina 2002 ja 2003.

Hypoteesin mukaisesti herneen viljelyn yleistyminen lisäsi hernekääriäisriskiä. Riskin kasvaminen lisää kasvinsuojelutarvetta. Hernekääriäismäärien suuri vuosittainen ja alueellinen vaihtelu (Ekholm 1963, Stenmark 1971, Van de Steene et al. 1999) vaikeuttavat riskin arviointia. Hernekääriäisen populaatiokokoon ja siitä aiheutuneiden tuhojen määrään vaikuttavat sääolosuhteet (etenkin lämpötila) sekä hernekääriäisen esiintymishuipun ja hernekasvuston kasvuvaiheen yhteensopiminen. Suuren vaihtelun vuoksi hernekääriäisen tarkkailu feromonipyydyksillä on välttämätöntä torjuntakynnyksen ja sopivan torjuntaajankohdan selvittämiseksi (Stenmark 1974, Tuovinen 1990). 
Hernekääriäisriskin vähentämiseksi pelkkä lohkokohtainen viljelykierto ei riitä, vaan ratkaisuksi suositellaan ns. alueellista viljelykiertoa ("area-wide pest management” Chandler \& Faust 1998). Riittävä etäisyys edellisvuoden hernelohkoon vähentää aikuisten hernekääriäisten siirtymistä talvehtimispaikoistaan uusille hernelohkoille.

\section{Herneenviljelyn laajentumisskenaariot}

Hernekääriäisriski riippuu herneen viljelyn laajuudesta, etenkin etäisyydestä lähimpään edellisvuoden hernelohkoon. Hernekääriäisriskin muutosta viljelyn laajetessa voidaan kuvata skenaariokartoilla. Nykyisellään hernekääriäisriski on suuri Etelä- ja Lounais-Suomessa (Kuva 4a). Viljelyn kaksinkertaistuminen lisää riskiä olennaisesti pääosin samalla alueella, mutta viljelyn nelinkertaistaminen laajentaa riskialueen jo koko eteläiseen Suomeen ja rannikkoalueelle (Kuva 4b).

Laajentumisskenaariot ovat riippuvaisia herneenviljelyn taloudellisuudesta. Ensisijaisesti viljelyala voi kasvaa tiloilla, jotka käyttävät rehuherneen kotieläinten rehuksi. Karjatilat sijaitsevat pääosin Itä- ja Keski-Suomessa, mutta suurin osa siipikarja- ja sikatiloista sijaitsee nykyisellä herneen pääviljelyalueella Lounais-Suomessa. Jos rehuteollisuus kiinnostuu herneestä kotimaisena proteiinilähteenä, herneen viljelyala kasvaa huomattavasti, todennäköisemmin viljantuotantoon erikoistuneilla tiloilla.

Hernekääriäisriskiskenaariossa on huomioitu vain peltojen välinen etäisyys, ei niiden pinta-alaa. Epäilemättä todelliseen riskiin vaikuttavat sekä edellisvuoden hernepeltojen etäisyys että pinta-ala. Lisäksi viljelymenetelmät, kuten kylvö- ja korjuuajankohta sekä kasvinsuojelu, vaikuttavat riskitasoon. Luomutuotannossa hernekääriäisen riski on suurempi ja sen torjunta hankalampaa kuin tavanomaisessa viljelyssä, joten luonnonmukaisesti viljellyn herneen viljelyala on myös huomioitava.
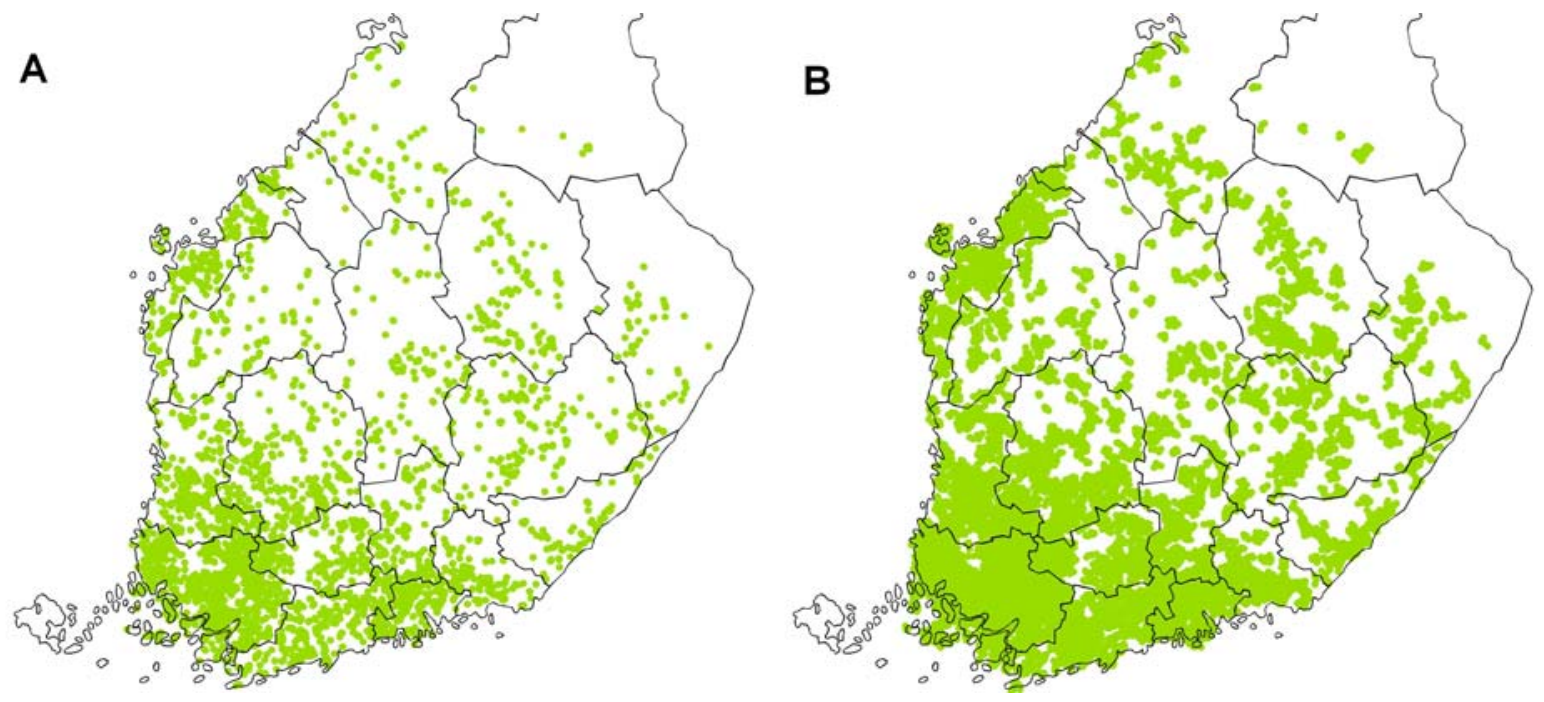

Kuva 4. Hernekääriäisriski Suomessa perustuen nykytilanteeseen (a. vuosi 2002) ja skenaarioon, jossa herneen viljely on nelinkertaistunut (b) Riskiä kuvattu hernelohkon ympärille varjostetulla ympyrällä, jonka säde 3 km.

\section{Johtopäätökset}

Tulosten perusteella hernekääriäisriski on selvästi suurempi alueilla, joilla herneen viljely on yleistä. Viljelyalan kasvu ja herneen viljely entistä useammin samoilla tai lähekkäisillä lohkoilla lisää selvästi hernekääriäisen aiheuttamien tuhojen määrää.

Oikein ajoitettu kemiallinen torjunta on yksi keino vähentää hernekääriäisen aiheuttamia satotappioita. Rehuherneen viljelyssä hernekääriäisellä ei kuitenkaan ole suurta taloudellista merkitystä eikä sitä yleensä torjuta. Rehuherneen viljelyn yleistyminen lisääkin ennen kaikkea lähialueella muihin käyttötarkoituksiin kasvatetun herneen hernekääriäisriskiä ja torjuntatarvetta. Herneen tuholaisongelmien ratkaisuksi lohkokohtainen kasvinvuorotus ei yksistään riitä, koska hernekääriäiset levittäytyvät viljelmille läheisiltä edellisvuoden hernelohkoilta. Hernekääriäisriskin pienentämiseksi uusi hernelohko pitäisi perustaa 
mahdollisimman etäälle, vähintään 1,5 km:n päähän, edellisvuoden hernelohkosta. Käytännön neuvona on, että hernettä pitäisi viljellä vuorovuosina eri viljelyaukeilla.

\section{Kirjallisuus}

Chandler, L.D. \& Faust, R.M. 1998. Overview of area-wide management of insects. Journal of Agricultural Entomology 15: 319-325

Ekholm, S. 1963. The pea moth (Laspeyresia nigricana Steph.), its fluctuations and distribution in Finland. Notulae Entomologicae 43:1-13.

Maatilatilastollinen vuosikirja 2003. Maa- ja metsätalousministeriön tietopalvelukeskus. Maa-, metsä- ja kalatalous 2003: 62.

Stenmark, A 1971. Studies on the pea moth (Laspeyresia nigricana Steph.) in central Sweden. I and II. Statens Växtskyddanstalt. Meddelanden 15(136): 1-47.

Stenmark, A. 1974. Studies on the pea moth (Laspeyresia nigricana Steph.) in central Sweden. Statens Växtskyddanstalt. Meddelanden 15(155): 451-475.

TIKE 2002. Maa- ja metsätalousministeriön tietopalvelukeskus Yhdennetty hallinto ja valvontajärjestelmä (IACS) 1997-2001.

TIKE 2004. Maa- ja metsätalousministeriön tietopalvelukeskus Yhdennetty hallinto ja valvontajärjestelmä (IACS) 2002-2003.

Tuovinen, T. 1990. Pheromone based monitoring of lepidopterous pests in Finland: experiences and possibilities. Proc. Conf. Insect Chem. Ecol., Tabor 1990. Academia Prague and SPB Acad. Pub. The Hague, 1991. p. 369-372. Van de Steene, F., Vulsteke, G. \& Callewaert, D. 1999. The occurrence of the pea moth Laspeyresia nigricana (F.) in pea crops in Belgium. Proceedings of the Section Experimental and Applied Entomology 10: 151-154.

Webster, R. \& Oliver, M. 2001. Geostatistics for Environmental Scientists. John Wiley\&Sons. Chichester, England. $271 \mathrm{p}$. 